\title{
High glucose suppresses the viability and proliferation of HTR-8/SVneo cells through regulation of the miR-137/PRKAA1/IL-6 axis
}

\author{
HAI-YAN PENG ${ }^{1}$, MING-QING LI ${ }^{2,3}$ and HUA-PING LI ${ }^{1}$ \\ ${ }^{1}$ Department of Gynecology and Obstetrics, Shanghai Jiao Tong University Affiliated Sixth People's Hospital, \\ Shanghai 200233; ${ }^{2}$ Laboratory for Reproductive Immunology, \\ Shanghai Key Laboratory of Female Reproductive Endocrine Related Diseases, \\ Obstetrics and Gynecology Hospital of Fudan University, Shanghai 200011; \\ ${ }^{3}$ Key Laboratory of Reproduction Regulation of NPFPC, SIPPR, IRD, Fudan University, \\ Shanghai 200032, P.R. China
}

Received December 1, 2017; Accepted April 27, 2018

DOI: $10.3892 /$ ijmm.2018.3686

\begin{abstract}
The aim of the present study was to investigate the mechanism underlying the high glucose $(\mathrm{HG})$-associated regulation of HTR-8/SVneo cell viability and proliferation during gestational diabetes mellitus (GDM), and to verify the association of microRNA (miR)-137, protein kinase AMP-activated catalytic subunit $\alpha 1$ (PRKAA1) and interlukin-6 (IL-6). miR-137-overexpressing and negative control HTR-8/SVneo cells were established by lentiviral vector infection. Cell Counting Kit- 8 and colony formation assays were used to analyze the viability and proliferation of HTR-8/SVneo cells. Reverse transcription-quantitative polymerase chain reaction analysis was used to determine the transcriptional activity of miR-137, PRKAA1 and Il-6, and ELISA and western blot analysis were used to measure the protein levels of IL-6 and PRKAA1, respectively. It was demonstrated that PRKAA1 was decreased in the placental tissues of women with GDM and HG-treated HTR-8/SVneo cells, and that HG upregulated miR-137 and IL-6 in trophoblasts. The overexpression of miR-137 decreased levels of PRKAA1 and increased levels of IL-6 in the HTR-8/SVneo cells. An inhibitor of PRKAA1 promoted the secretion of IL-6, whereas an agonist of PRKAA1 suppressed the production of IL-6. HG treatment and the overexpression of miR-137 reduced the viability and proliferation of HTR-8/SVneo cells in vitro, whereas the activation of PRKAA1 or incubation with IL-6 antibody reversed these effects. Overall, it was concluded that HG suppressed
\end{abstract}

Correspondence to: Dr Hua-Ping Li, Department of Gynecology and Obstetrics, Shanghai Jiao Tong University Affiliated Sixth People's Hospital, 600 Yishan Road, Shanghai 200233, P.R. China E-mail: lihp@sjtu.edu.cn

Key words: high glucose, HTR-8/SVneo, microRNA-137, viability, protein kinase AMP-activated catalytic subunit $\alpha 1$, interleukin- 6 the viability and proliferation of trophoblast cells through the miR-137/PRKAA1/IL-6 axis, which may contribute to pathological changes of placental tissues in GDM.

\section{Introduction}

Diabetes during pregnancy refers to two conditions, namely pre-gestational diabetes and gestational diabetes mellitus (GDM). The former comprises diabetes prior to conception, including type 1 diabetes mellitus and type 2 diabetes mellitus (T2DM), and the latter refers to impaired glucose tolerance that is initiated during pregnancy, which is the greatest contributor to cases of diabetes during pregnancy. GDM is characterized by hyperglycemia and disturbance of carbohydrate metabolism, and the etiology and pathological changes may be largely different from T2DM (1). Poorly controlled GDM may result in maldevelopment and incorrect vascular remodeling of the placenta. Previous studies have suggested that maternal hyperglycemia at early stages of pregnancy may facilitate abortion and fetus malformation, in addition to abnormal development of the first trimester placental tissue $(2,3)$, which may be ascribed to the effect of high glucose (HG) on the placenta. As a crucial organ for nutrition exchange between mother and fetus during pregnancy, the regular formation, implantation and growth of the placenta are important to assure healthy pregnancy maintenance and embryonic development (4). Trophoblast cells of normal biological function are vital to the development of the placenta. Suppressed invasion, migration and viability of trophoblast cells may contribute to maldevelopment of placental tissues, resulting in miscarriage, spontaneous abortion and premature labor, which have been reported in several published studies over the years (5-7). However, the mechanisms involved in the inhibition of trophoblast cell viability and proliferation in GDM remain to be fully elucidated.

Protein kinase AMP-activated catalytic subunit $\alpha 1$ (PRKAA1), also termed AMP-activated protein kinase (AMPK) or AMPK 1 , is an enzyme of the serine/threonine 
kinase family, which mediates the activities of essential metabolic enzymes by phosphorylation. PRKAA1 is important in glucose metabolism and energy homeostasis; it also interferes with the modulation of biological functions of cells (7). Previous studies have reported that PRKAA1 is aberrantly expressed in women with GDM and HG-treated vascular endothelial cells $(8,9)$. Regarding potential upstream regulators of PRKAA1, microRNAs (miRNAs) are of interest in research. These are conserved endogenous, non-coding RNAs of 20-25 nucleotides, which bind to the 3' untranslated region of target mRNAs to induce silencing and repression of translation, thus regulating various metabolic pathways. Such activity contributes to the pathology of numerous diseases (10). Notably, it has been indicated that the fetus may retain metabolic memory of $\mathrm{HG}$ conditions and maintain the same pattern of metabolism, even if maternal glucose is controlled well in later gestational weeks (11). This phenomenon is termed 'fetal programming' and is associated with a long-term risk of suffering from other complications, which may be ascribed to genetic factors (12). It has previously been reported that miR-137 is abnormally expressed in the placental tissues of women with GDM and preeclampsia, and is involved in HG-induced dysfunction of vascular endothelial cells via the downregulation of PRKAA1 $(13,14)$, which may be involved in exacerbating the progression of diseases and render a higher risk of cardiovascular events for the mother and fetus in later life. Interleukin-6 (IL-6) is a downstream molecule, which may be regulated by PRKAA1 and has been revealed to be modulated by PRKAA1 in different types of cells; furthermore, its levels are elevated in patients with GDM, contributing to the low-grade inflammatory status of individuals (15-18). However, the influence of PRKAA1 on the viability and proliferation of trophoblast cells remains to be elucidated.

In order to investigate the mechanism underlying aberrant PRKAA1 levels that potentially result in maldevelopment of the placenta in women with GDM, the present study detected the expression profile of PRKAA1 in the placental tissues of healthy women and women with GDM, and evaluated the role of the microRNA (miR)-137/PRKAA1/IL-6 axis in regulating the viability and proliferation of HTR-8/SVneo human trophoblast cells under a HG condition in vitro. The aim of the present study was to provide a possible mechanism to elucidate how dysfunction of the placental tissue occurs during the gestational diabetic period.

\section{Materials and methods}

Participants and biopsy collection. The present study was approved by the Ethics Committee of Shanghai Jiao Tong University Affiliated Sixth People's Hospital (Shanghai, China) and all participants were recruited between January and June 2017 in the Department of Gynecology and Obstetrics, with informed consent. The participants (age, 20-40) with GDM were diagnosed according to the American Diabetes Association guidelines (19), with healthy pregnant women being recruited as controls. Patients with pre-gestational diabetes, multiple gestation accompanied with further complications, and/or taking medication were all excluded from the study. At the time of delivery, placental biopsies of the women with GDM $(n=11)$ and healthy women $(n=11)$ were collected and transferred to the laboratory immediately, and stored in liquid nitrogen prior to extraction of protein.

Cell culture. The HTR-8/SVneo trophoblast cell line derived from human choriocarcinoma was purchased from the Chinese Academy of Sciences Cell Bank (Shanghai, China) and cultured in Dulbecco's modified Eagle's medium (including 1,000 mg/l glucose; Invitrogen; Thermo Fisher Scientific, Inc., Waltham, MA, USA), supplemented with $10 \%$ fetal bovine serum (ScienCell Research Laboratories, Inc., San Diego, CA, USA), $100 \mathrm{U} / \mathrm{ml}$ penicillin and $100 \mu \mathrm{g} / \mathrm{ml}$ streptomycin (Sangong Biotech, Co., Ltd., Shanghai, China) and $0.25 \mu \mathrm{g} / \mathrm{ml}$ amphotericin B (Sigma-Aldrich; Merck Millipore, Darmstadt, Germany). The cells were incubated at $37^{\circ} \mathrm{C}$, in a humidified atmosphere containing $5 \% \mathrm{CO}_{2}$. Additional D-glucose (Sigma-Aldrich; Merck Millipore) was dissolved in the supplemented medium up to a final glucose concentration of $25 \mathrm{mmol} / \mathrm{l}$, following which the $\mathrm{HG}$ medium was prepared in which cells were cultured, with cells in normal medium (glucose concentration $\sim 5 \mathrm{mmol} / \mathrm{l}$ ) used as a control.

Lentiviral vector infection. Recombinant lentiviral vectors with Ubi-MCS-SV40-EGFP-IRES-puromycin sequences of LV-miR-NC (LV-NC; cat. no. LVCON238) and up-LV-miR-137 (LV-miR-137; cat. no. LVKL15932-1) were constructed by Shanghai GeneChem Co., Ltd. (Shanghai, China). The HTR-8/SVneo cells were uniformly planted in a 6-well culture plate (Corning Incorporated, Corning, NY, USA) with $5 \times 10^{5}$ cells per well. After $24 \mathrm{~h}$, the medium was replaced with infection substrates in accordance with the recommended protocol. Following $96 \mathrm{~h}$ of infection, light from green fluorescent protein (GFP) was observed under an Olympus BX51 fluorescence microscope (Olympus Corporation, Tokyo, Japan). Puromycin (Shanghai GeneChem Co., Ltd.) was added into the medium to clear out uninfected cells for $\sim 2$ weeks, and stably infected surviving cells were measured for infection efficiency and cultured for further experiments.

Cell Counting Kit-8 (CCK-8) viability assay. The LV-NC and LV-miR-137 groups of HTR-8/SVneo cells were plated in a 96-well culture plate (Corning Incorporated) at the same density, and incubated at $37^{\circ} \mathrm{C}$ in a humidified atmosphere containing $5 \% \mathrm{CO}_{2}$ for $24 \mathrm{~h}$. The uninfected HTR-8/SVneo cells were uniformly planted in several 96 -well plates (Corning Incorporated), and different concentrations of IL-6 (15.0, 30.0, 37.5, 45.0 and 52.5 pg/ml; BioLegend, Inc., San Diego, CA, USA), PRKAA1 inhibitor (Dorsomorphin; MedChemExpress, Princeton, NJ, USA), PRKAA1 agonist (AICAR; MedChemExpress) and IL-6 antibody ( $\alpha$-IL-6; BioLegend, Inc.) were solely or jointly added to the medium for $24 \mathrm{~h}$ of treatment. The viability of the HTR-8/SVneo cells was determined using a CCK-8 assay (Dojindo Molecular Technologies, Inc., Kumamoto, Japan). At the time of detection, the medium was removed and the cells were washed with PBS, following which $10 \mu \mathrm{l}$ CCK-8 and $90 \mu 1$ medium was added into each well of the plate. Following incubation at $37^{\circ} \mathrm{C}$ for 1-4 $\mathrm{h}$ in the dark, the plates were transferred to a microplate spectrometer (BioTek Instruments, Inc., Winooski, VT, USA) to measure optical density (OD) at a wavelength of $450 \mathrm{~nm}$. 
Table I. Sequences of forward and reverse primers for target genes.

\begin{tabular}{|c|c|c|}
\hline Gene & Direction & Sequence $\left(5^{\prime}-3^{\prime}\right)$ \\
\hline \multirow[t]{2}{*}{ miR-137 } & Forward & ATAGAGCGGCCATTTGGATT \\
\hline & Reverse & TCAAGGCCTTTCAGTCGTTC \\
\hline \multirow[t]{2}{*}{ hsa-u6 } & Forward & CTCGCTTCGGCAGCACA \\
\hline & Reverse & AACGCTTCACGAATTTGCCT \\
\hline \multirow[t]{2}{*}{ PRKAA1 } & Forward & TGTAAGAATGGAAGGCTGGATGA \\
\hline & Reverse & GGACCACCATATGCCTGTGA \\
\hline \multirow[t]{2}{*}{ IL-6 } & Forward & GCTTCTTAGCGCTAGCCTCAATG \\
\hline & Reverse & TGGGGCTGATTGGAAACCTTATTA \\
\hline \multirow[t]{2}{*}{$\beta$-actin } & Forward & TGGCACCCAGCACAATGAA \\
\hline & Reverse & CTAAGTCATAGTCCGCCTAGAAGCA \\
\hline
\end{tabular}

miR, microRNA; PRKAA1, protein kinase AMP-activated catalytic subunit $\alpha 1$; IL-6, interleukin-6.

The viability index was calculated as follows: Treatment group $^{\mathrm{OD} 450 \mathrm{~nm}} /$ Control group ${ }^{\mathrm{OD} 450 \mathrm{~nm}} \times 100 \%$.

Colony formation assay. The uninfected, LV-NC and LV-miR-137 groups of HTR-8/SVneo cells were plated at a density of $600-800$ cells/well into a 6 -well culture plate (Corning Incorporated) and cultured at $37^{\circ} \mathrm{C}$ in an atmosphere containing $5 \% \mathrm{CO}_{2}$, with exchange of the culture medium every other day. The uniformly plated uninfected HTR-8/SVneo cells were cultured with IL- 6 antibody ( $\alpha$-IL-6; 1:1,000; BioLegend, Inc.) supplementary medium at $37^{\circ} \mathrm{C}$, with HTR-8/SVneo cells not treated with $\alpha-\mathrm{IL}-6$ as a control group. The LV-NC and LV-miR-137 HTR-8/SVneo cells were cultured with normal and HG medium. After 10 days, the medium was removed from each well, and the plate was washed with PBS. The cells were then fixed with $4 \%$ paraformaldehyde (Biotech Well, Shanghai, China) for $10 \mathrm{~min}$. Following the fixation process, crystal violet hydrate solution (Sangong Biotech, Co., Ltd.) was added for cell staining for $30 \mathrm{~min}$. Finally, images of each well were captured by a camera (E-M1 Mark II; Olympus Corporation;) and colonies were counted, with a colony defined as $>15$ cells.

RNA extraction and reverse transcription (RT). The HTR-8/SVneo cells were plated in 6-well culture plate (Corning Incorporated), with normal medium-cultured cells as controls and HG medium-cultured cells as a HG group. To verify lentiviral vector infection efficiency and the role of overexpressed miR-137 in regulating the expression of PRKAA1 and Il-6, the uninfected, LV-NC, and LV-miR-137 groups of HTR-8/SVneo cells were equally plated in a 12-well culture plate (Corning Incorporated). Total RNAs in the placental tissues and cells were extracted using TRIzol ${ }^{\circledR}$ (Invitrogen; Thermo Fisher Scientific, Inc.). Following quantification with a microplate spectrometer (BioTek Instruments, Inc.), the RNAs were reverse transcribed to cDNA with quantification of $500 \mathrm{ng}$, using an miRcute miRNA First-Strand cDNA Synthesis kit (Tiangen Biotech Co., Ltd., Beijing, China) for miRNA analysis and PrimeScript RT Master mix (Perfect Real-Time; Takara Biotechnology Co., Ltd., Dalian, China) for mRNA detection, with the products from these processes stored at $-20^{\circ} \mathrm{C}$ in a refrigerator for subsequent assays.

Quantitative polymerase chain reaction ( $q P C R)$ analysis. The products of cDNA obtained from the aforementioned samples, including the control and HG groups, and LV-NC and LV-miR-137 HTR-8/SVneo cells, were used for RT-qPCR analysis. The reaction system for miRNA included $2 \mathrm{X}$ miRNA Plus miRNA Premix $(10 \mu \mathrm{l})$, forward primer $(0.4 \mu \mathrm{l})$, reverse primer $(0.4 \mu \mathrm{l})$, cDNA $(2 \mu \mathrm{l}), 50 \mathrm{X}$ ROX Reference Dye $(2 \mu \mathrm{l})$ and double distilled water $(5.2 \mu \mathrm{l})$. The mRNA reaction mixture included SYBR Premix EX Taq II (10 $\mu 1)$, forward primer $(0.8 \mu \mathrm{l})$, reverse primer $(0.8 \mu \mathrm{l})$, cDNA $(2 \mu \mathrm{l})$, ROX Reference Dye II $(0.4 \mu \mathrm{l})$ and double distilled water $(6 \mu \mathrm{l})$. The total volume of $20 \mu \mathrm{l}$ for each well was added into a 96-well plate (Corning Incorporated) according to the manufacturer's protocol. The reaction steps were set up in accordance with the protocol of the miRcute miRNA qPCR Detection kit (SYBR Green; TianGen Biotech Co., Ltd.) for miRNA, with hsa-u6 as an internal control, and of SYBR Premix EX Taq ${ }^{\mathrm{TM}}$ II (Tli RAaseH Plus; Takara Biotechnology Co., Ltd) for mRNA, with the housekeeping gene $\beta$-actin as an internal control. The reaction conditions for mRNA were set as: $95^{\circ} \mathrm{C}$ for $30 \mathrm{sec}$, $95^{\circ} \mathrm{C}$ for $5 \mathrm{sec}$ for 40 cycles, $60^{\circ} \mathrm{C}$ for $34 \mathrm{sec}$ and a final stage at $95^{\circ} \mathrm{C}$ for $15 \mathrm{sec}, 60^{\circ} \mathrm{C}$ for $1 \mathrm{~min}, 95^{\circ} \mathrm{C}$ for $15 \mathrm{sec}$. The reaction conditions for the miRNAs were: $95^{\circ} \mathrm{C}$ for $15 \mathrm{~min}, 94^{\circ} \mathrm{C}$ for $20 \mathrm{sec}$ for $40 \mathrm{cycles}, 60^{\circ} \mathrm{C}$ for $34 \mathrm{sec}$, and a final stage at $95^{\circ} \mathrm{C}$ for $15 \mathrm{sec}, 60^{\circ} \mathrm{C}$ for $1 \mathrm{~min}, 95^{\circ} \mathrm{C}$ for $15 \mathrm{sec}$. These steps were processed using the 7500 Real-Time PCR system (Applied Biosystems; Thermo Fisher Scientific, Inc.). The relative expression of target genes was analyzed using the $2^{-\Delta \Delta C q}$ method (20). The forward and reverse primer sequences used are listed in Table I. All primers were purchased from Sangong Biotech, Co., Ltd.

ELISA. The uninfected HTR-8/SVneo cells were plated in three 24-well culture plates (Corning Incorporated), and he LV-NC, and LV-miR-137 groups of HTR-8/SVneo cells were plated in a new 24-well plate (Corning Incorporated). After $24 \mathrm{~h}$, the medium of the control, LV-NC, and LV-miR-137 
HTR-8/SVneo cells was exchanged with $500 \mu$ new medium, with the HG group receiving HG medium. The media in the second and third uninfected culture plates were respectively replaced with $500 \mu \mathrm{l}$ of medium containing different concentrations of dorsomorphin $(0,2.5,5$ and $10 \mu \mathrm{M})$ and AICAR $(0,0.10,0.25$ and $0.50 \mathrm{mM})$. The cells were then incubated in $5 \% \mathrm{CO}_{2}$ at $37^{\circ} \mathrm{C}$ for $24 \mathrm{~h}$. The medium was collected and centrifuged at $400 \mathrm{xg}$ and $4^{\circ} \mathrm{C}$ for $20 \mathrm{~min}$, following which the supernatants were isolated. A human IL-6 ELISA kit (Dakewe Biotech Co., Ltd., Shenzhen, China, cat. no. DKW12-1060-096 was used to measure the concentration of IL-6 in the supernatant according to the manufacturer's protocol. Following this, the OD values at wavelengths of 450 and $570 \mathrm{~nm}$ were determined using a microplate spectrometer (BioTek Instruments, Inc.) and the final concentrations of IL-6 in supernatants were calculated according to the standard curve.

Western blot analysis. The uninfected HTR-8/SVneo cells were cultured in a 6-well plate (Corning Incorporated) and the LV-NC, and LV-miR-137 HTR-8/SVneo cells were cultured in another 6-well plate. When all cells had grown to $80 \%$ confluence, the uninfected HTR-8/SVneo cells were divided into control and HG groups. The medium of the HG group was replaced with $\mathrm{HG}$ medium, whereas the culture media of the other groups remained as normal. Following $24 \mathrm{~h}$ treatment and incubation, the culture medium was removed and the cells were washed with PBS three times. The placental biopsies were removed from liquid nitrogen and used to extract protein. A total of $60 \mu \mathrm{l}$ radioimmunoprecipitation assay lysis buffer (Beyotime Institute of Biotechnology, Haimen, China) with phenylmethanesulfonyl fluoride (Beyotime Institute of Biotechnology) was added to each sample on ice for $30 \mathrm{~min}$, following which the cells were scratched with a cell scraper, and protein liquid was transferred into $1.5 \mathrm{ml} \mathrm{EP}$ tubes, prior to centrifugation at $2,000 \mathrm{x} \mathrm{g}$ and $4^{\circ} \mathrm{C}$ for $20 \mathrm{~min}$. The supernatants were collected and the concentration of protein was determined with an enhanced bicinchoninic acid assay protein kit (Beyotime Institute of Biotechnology). The extracted protein was boiled with SDS-PAGE sample loading buffer (Beyotime Institute of Biotechnology) for $10 \mathrm{~min}$. For the western blot assay, $25 \mu \mathrm{g}$ of protein samples and marker/ladder (Invitrogen; Thermo Fisher Scientific, Inc.) in 10\% SDS-PAGE (EpiZyme, Inc., Shanghai, China) underwent electrophoresis and transmembrane blotting, in which the separated proteins of different molecular weights were transferred onto $0.45-\mu \mathrm{m}$ polyvinylidene membranes (Biotech Well). The membranes were then blocked in 5\% defatted milk (Yili Group, Beijing, China) for $2 \mathrm{~h}$ at room temperature and washed with Tris-buffered saline Tween-20 (TBST; Biotech Well). Rabbit monoclonal antibodies against $\beta$-actin (Cell Signaling Technology, Inc., Danvers, MA, USA, cat. no. 8457) and PRKKA1 (Cell Signaling Technology, Inc., cat. no. 2795S) were diluted in primary antibody dilution buffer (Beyotime Institute of Biotechnology) at a ratio of 1:1,000, and the membranes were incubated in the antibody solution at $4^{\circ} \mathrm{C}$ overnight. Following this incubation process, the membranes were washed with TBST and incubated with HRP-linked anti-rabbit antibody (Cell Signaling Technology, Inc., cat. no. 7074S), diluted in secondary antibody dilution buffer (Beyotime Institute of Biotechnology) at a ratio of 1:5,000, at room temperature for $1 \mathrm{~h}$. Finally, the membranes were exposed to an enhanced chemiluminescence western blotting substrate kit (EMD Millipore, Billerica, MA, USA) using chemiluminescence apparatus. Relative protein band density was determined with Image Pro Plus version 6.0 (Media Cybernetics, Inc., Rockville, MD, USA).

Statistical analysis. Statistical analysis was performed with GraphPad Prism version 5 (GraphPad Software, Inc., La Jolla, CA, USA) and data are presented as the mean \pm standard error of the mean. Statistical significance was determined using Student's t-test or one-way analysis of variance with post hoc comparisons with the Student-Newman-Keuls test. $\mathrm{P}<0.05$ was considered to indicate a statistically significant difference.

\section{Results}

Expression of PRKAA1 is decreased in placental tissues of women with GDM. To examine the expression profile of PRKAA1 in the placental tissues of women with GDM and healthy women, and to reveal its potential role in mediating dysfunction of the placenta, which frequently occurs during the gestational diabetic period, a western blot assay was used to determine the protein production levels of PRKAA1 in biopsies. As shown in Fig. 1A and B, compared with the specimens collected from healthy women $(n=11)$, the protein levels of PRKAA1 were notably decreased in the placental tissues of the women with GDM ( $n=11)$. This may be associated with pathological changes of placental tissues and adverse pregnancy outcomes in GDM.

$H G$ treatment suppresses the expression of PRKAAl and upregulates levels of miR-137 and IL-6. In order to verify the role of PRKAA1 in regulating the biological function of placental tissues and the underlying mechanism under conditions of hyperglycemia, the HTR-8/SVneo trophoblast cell line was treated with $\mathrm{HG}$ medium for $24 \mathrm{~h}$ in vitro. Following this, RT-qPCR analysis was performed to determine the expression levels of PRKAA1 and its potential regulator, miR-137, and western blot analysis and ELISA were performed to detect the protein levels of PRKAA1 and IL-6, respectively. The results, as shown in Fig. 2A and B, revealed that treatment with $\mathrm{HG}$ significantly decreased the level of PRKAA1 and upregulated the level of miR-137 in the HTR-8/SVneo cells $(\mathrm{P}<0.05$, $\mathrm{P}<0.001)$. As shown in Fig. 2C-E, decreased protein level of PRKAA1 and elevated secretion of IL-6 were observed in the HG-exposed HTR-8/SVneo cells.

Upregulating miR-137 decreases the expression of PRKAAI in HTR-8/SVneo cells. PRKAA1 is involved in numerous signaling pathways and has been revealed as a target gene of miR-137 in human umbilical vein endothelial cells (21-23). To further investigate whether the suppressed expression of PRKAA1 is modulated by augmented miR-137 in HTR-8/SVneo cells under HG conditions, the present study used the LV-NC and LV-miR-137 lentiviral vectors to infect HTR-8/SVneo cells. RT-qPCR analysis was used to detect the expression levels of PRKAA1 and the efficiency of the upregulation of miR-137, with protein levels of PRKAA1 measured using western blot analysis. The results, as shown in Fig. 3A, revealed the successful infection efficiency of the lentiviral 
A

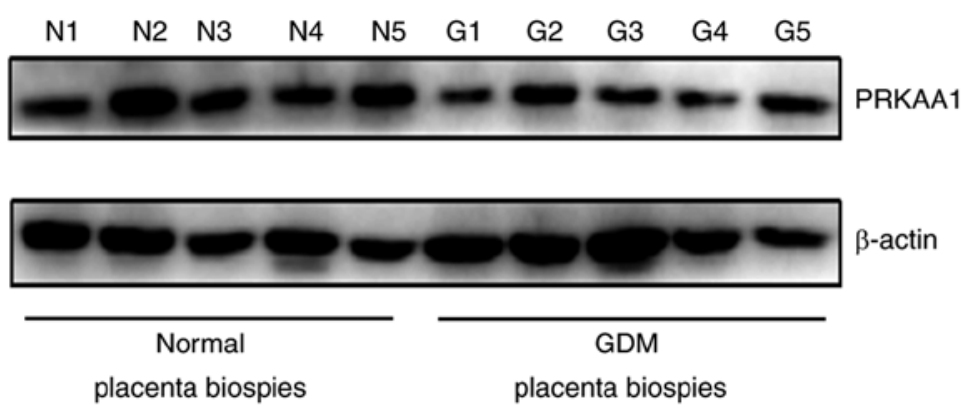

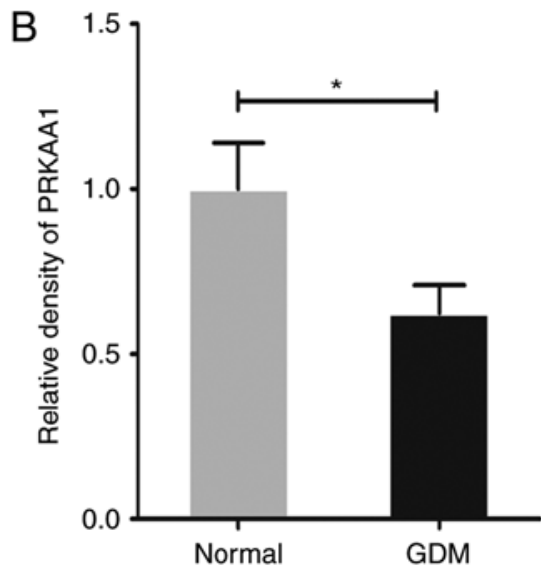

Figure 1. PRKAA1 is decreased in placental tissues of women with GDM. Western blot analysis was used to measure the protein level of PRKAA1 in placental tissues of women without GDM $(\mathrm{n}=11)$ and with GDM $(\mathrm{n}=11)$. $\beta$-actin $(\sim 43 \mathrm{kDa})$ was used as the internal control. The relative density of PRKAA1 $(\sim 62 \mathrm{kDa})$ was determined with Image Pro Plus version 6.0 software. (A) Representative protein bands of PRKAA1 and $\beta$-actin in placental biopsies of five normal pregnant women and five women with GDM. (B) Relative density of PRKAA1 in placental tissues of the normal (n=11) and GDM (n=11) groups. Data are expressed as the mean \pm standard error of the mean; statistical significance was determined using Student's $\mathrm{t}$-test, ${ }^{*} \mathrm{P}<0.05$. GDM, gestational diabetes mellitus; PRKAA1, protein kinase AMP-activated catalytic subunit $\alpha 1$; N, normal; G, GDM.

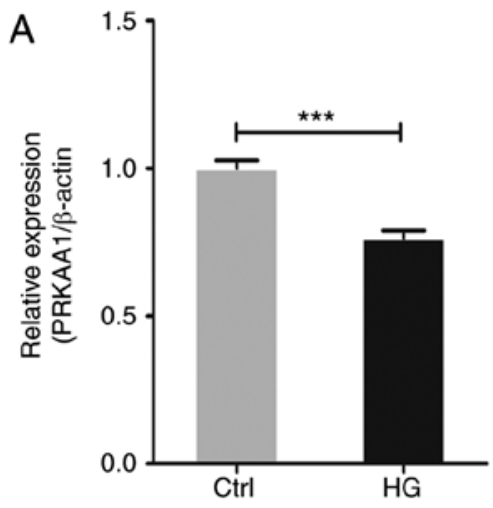

$\mathrm{D}$

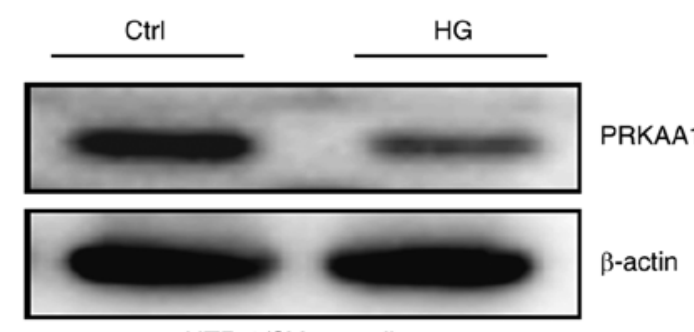

B

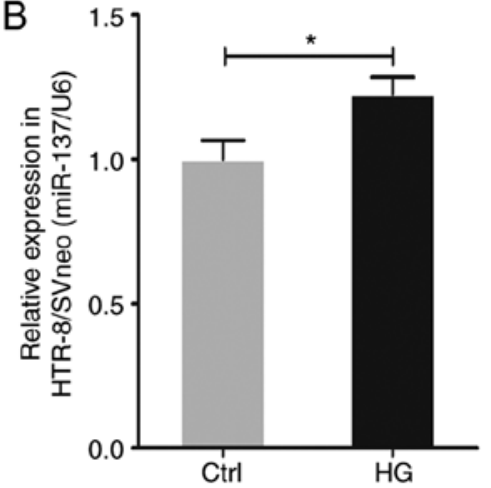

C

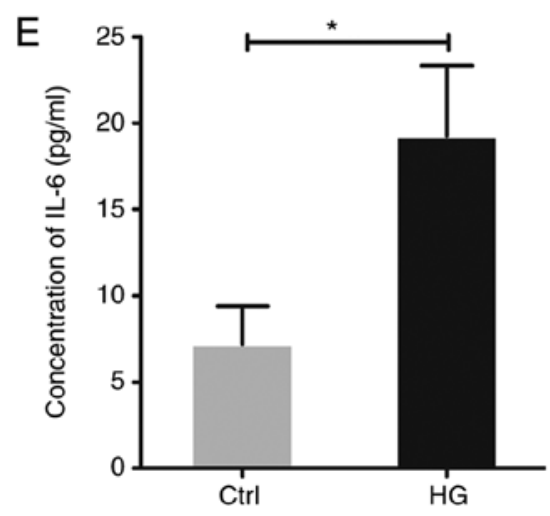

Figure 2. HG treatment suppresses the expression of PRKAA1 and upregulates levels of miR-137 and IL-6. HTR-8/SVneo trophoblastic cells were treated with HG $(25 \mathrm{mmol} / \mathrm{l})$ medium for $24 \mathrm{~h}$, with a control group cultured in normal medium $(5 \mathrm{mmol} / \mathrm{l})$. Expression levels of miR-137 and PRKAA1 were detected using reverse transcription-quantitative polymerase chain reaction analysis, with hsa-u6 and $\beta$-actin as internal controls. Protein levels of PRKAA1 $(\sim 62 \mathrm{kDa})$ and IL-6 were measured using western blot analysis and ELISA, respectively, and the relative density of PRKAA1 was determined using Image Pro Plus 6.0 software. (A) HG intervention suppressed the expression of PRKAA1 in HTR-8/SVneo cells. (B) miR-137 expression levels were elevated in HG-exposed HTR-8/SVneo cells. (C) Protein level of PRKAA1 was decreased in HG-exposed HTR-8/SVneo cells. (D) Results of western blot analysis. (E) HG treatment promoted the secretion of IL-6 in HTR-8/SVneo cells. Data are expressed as the mean \pm standard error of the mean; statistical significance was determined using Student's t-test, ${ }^{*} \mathrm{P}<0.05,{ }^{* * *} \mathrm{P}<0.001$. HG, high glucose; $\mathrm{Ctrl}$, control; miR-137, microRNA-137; PRKAA1 protein kinase AMP-activated catalytic subunit $\alpha 1$; IL-6, interleukin- 6 .

vectors $(\mathrm{P}<0.05, \mathrm{P}<0.01)$, and indicated that the upregulation of miR-137 in HTR-8/SVneo cells decreased the expression of PRKAA1 at the gene and protein levels (Fig. 3B-D; P<0.05).
HG/miR-137 elevates the expression of IL-6 in HTR-8/SVneo cells by downregulating PRKAA1. To investigate whether the elevated secretion of IL-6 in HG-stimulated HTR-8/SVneo 
A

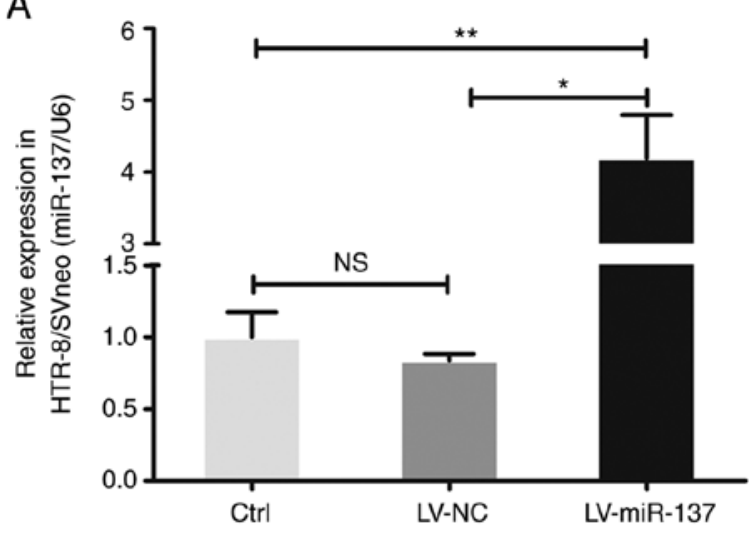

C

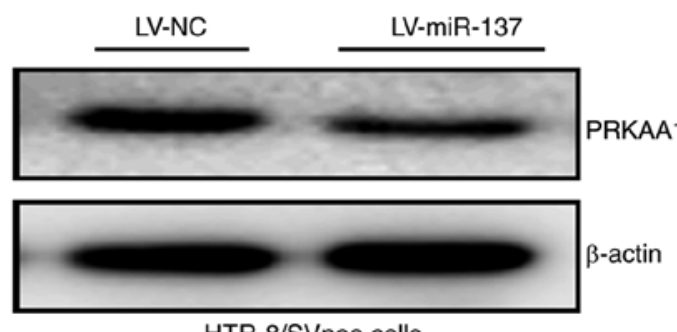

B

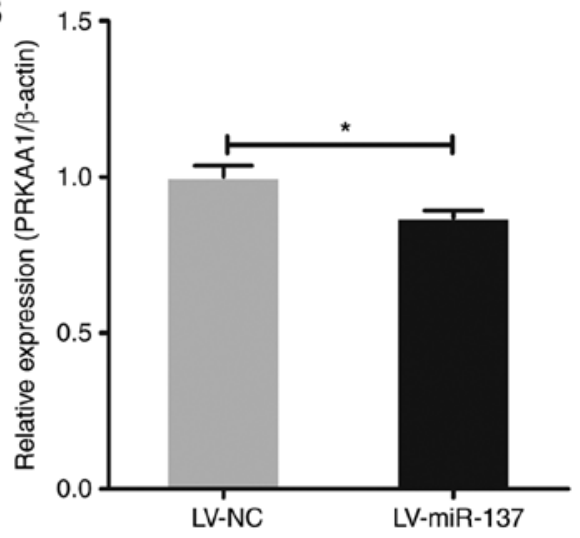

D

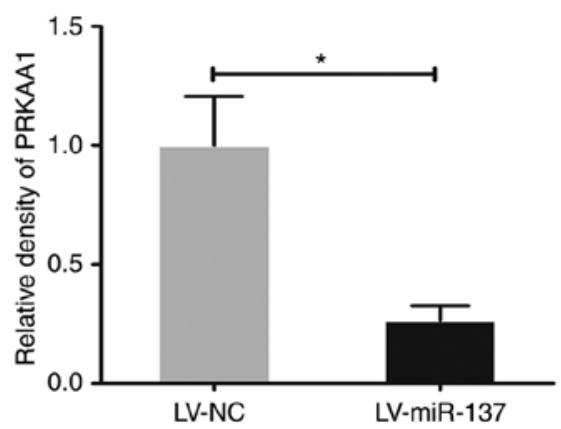

Figure 3. miR-137 upregulation decreases levels of PRKAA1 in HTR-8/SVneo cells. HTR-8/SVneo cells were infected with lentiviral vectors and miR-137 and PRKAA1 gene expression levels were measured using reverse transcription-quantitative polymerase chain reaction analysis, with hsa-u6 and $\beta$-actin as internal controls, respectively. Protein levels of PRKAA1 ( $62 \mathrm{kDa})$ were detected by western blot analysis, and $\beta$-actin $(\sim 43 \mathrm{kDa})$ was used as an internal control. (A) miR-137 was upregulated in LV-miR-137 HTR-8/SVneo cells. (B) Gene expression level of PRKAA1 was downregulated in the LV-miR-137 group. (C) Western blot analysis of PRKAA1. (D) Protein level of PRKAA1 was decreased in miR-137-overexpressing HTR-8/SVneo cells. Data are expressed as the mean \pm standard error of the mean; statistical significance was determined using Student's t-test, ${ }^{*} \mathrm{P}<0.05,{ }^{* *} \mathrm{P}<0.01$. Ctrl, control; NS, no significant difference; miR-137, microRNA-137; PRKAA1 protein kinase AMP-activated catalytic subunit $\alpha 1$; LV, lentiviral vector; NC, negative control.

cells was triggered by miR-137/PRKAA1, the production of IL-6 at the gene and protein levels was measured using RT-qPCR analysis and ELISA, respectively. The results, as shown in Fig. 4A and B, revealed that the overexpression of miR-137 upregulated the expression of IL-6 in HTR-8/SVneo cells $(\mathrm{P}<0.05$ and $\mathrm{P}<0.01)$. To investigate whether PRKAA1 is involved in modulating the expression of IL-6, different concentrations of inhibitor (dorsomorphin) and agonist (AICAR) of PRKAA1 were used to treat the HTR-8/SVneo cells for $24 \mathrm{~h}$. The results, as shown in Fig. $4 \mathrm{C}$ and D, clarified that the inhibition of PRKAA1 by dorsomorphin upregulated the expression of IL-6, whereas the agonist of PRKAA1 caused the reverse effect $(\mathrm{P}<0.01$ and $\mathrm{P}<0.001)$. It was concluded that HG treatment upregulated miR-137, which downregulated PRKKA1 and ultimately promoted the production of IL-6 in the HTR-8/SVneo cells.

HG/miR-137 reduces the viability and proliferation of HTR-8/Svneo cells. To investigate the effect of HG treatment and subsequent upregulation of miR-137 on the HTR-8/SVneo cells, the viability and proliferation were determined in HTR-8/SVneo cells (LV-NC and LV-miR-137 groups), separately cultivated in normal and $\mathrm{HG}$ medium. The viability and proliferation of the cells were detected using CCK-8 and colony formation assays. The results (Fig. 5A) and the statistical results of the colony formation assay (Fig. 5B) revealed that the proliferation of HTR-8/SVneo cells was reduced by the overexpression of miR-137 and/or HG treatment, compared with cells in the LV-NC group cultivated in normal conditions $(\mathrm{P}<0.01$ and $\mathrm{P}<0.001)$. In addition, the results of the CCK-8 assay (Fig. 5C) demonstrated that upregulating miR-137 in the HTR-8/SVneo cells significantly suppressed the viability of the cells $(\mathrm{P}<0.001)$. These results indicated that the HG-mediated upregulation of miR-137 reduced the viability and proliferation of the HTR-8/SVneo cells.

miR-137 suppresses the viability of HTR-8/SVneo cells by downregulating PRKAAl and upregulating IL-6. Based on the aforementioned results, it was hypothesized that HG stimulation induced high expression levels of miR-137, which downregulated PRKAA1 and increased IL-6. This led to the investigation of whether the miR-137/PRKAA1/IL-6 signaling pathway interferes with the HG-induced suppression of viability in HTR-8/SVneo cells. The results (Fig. 6A) suggested that IL-6 suppressed the viability of HTR-8/SVneo cells $(\mathrm{P}<0.05, \mathrm{P}<0.01$ and $\mathrm{P}<0.001)$, with the inhibitor of PRKAA1 (dorsomorphin) having the same effect $(\mathrm{P}<0.001$; Fig. 6B). As shown in Fig. 6C, the PRKAA1 agonist (AICAR) promoted the viability of HTR-8/SVneo cells $(\mathrm{P}<0.05$ and $\mathrm{P}<0.01)$. As shown in Fig. 6D, AICAR reversed the suppression of viability observed in HTR-8/SVneo cells overexpressing miR-137 $(\mathrm{P}<0.05$ and $\mathrm{P}<0.01)$. These results suggested that $\mathrm{HG}$ reduced the viability and proliferation of HTR-8/SVneo cells by upregulating miR-137 and IL-6, and downregulating PRKAA1. 
A

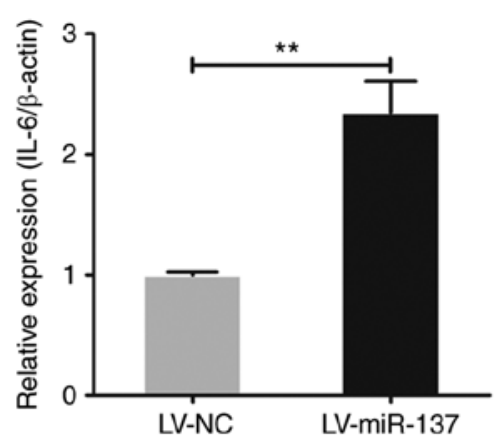

C

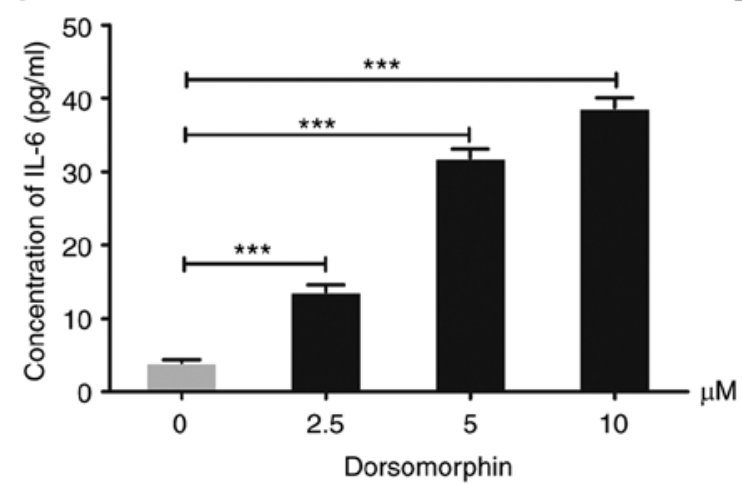

B

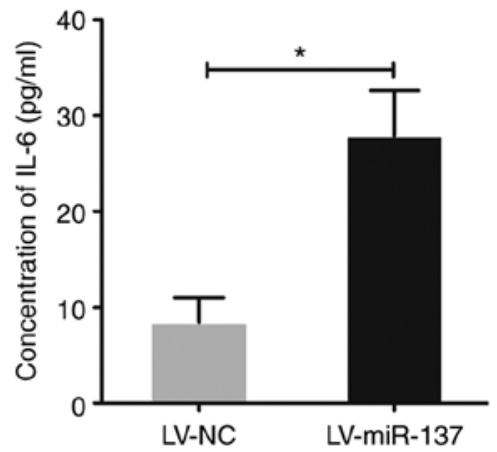

D

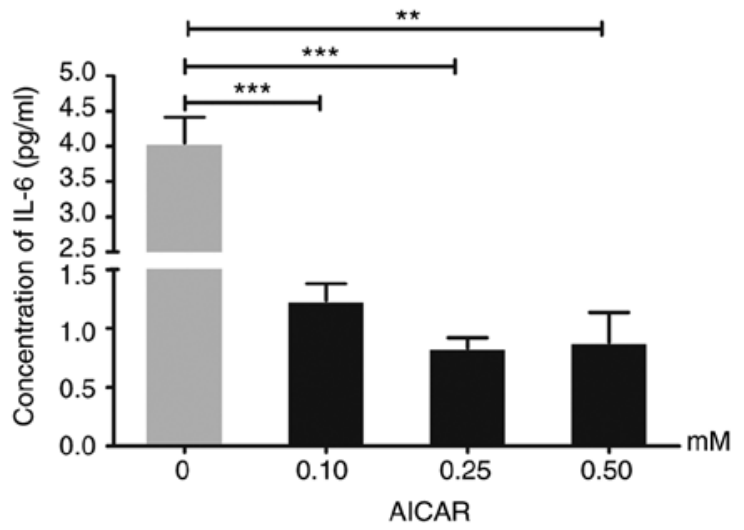

Figure 4. HG/miR-137 elevates levels of IL-6 in HTR-8/SVneo cells by decreasing PRKAA1. Expression levels of IL-6 in LV-NC and LV-miR-137 HTR-8/SVneo cell groups were detected using reverse transcription-quantitative polymerase chain reaction analysis. Secretion of IL-6 into the supernatants of miR-137-overexpressing, PRKAA1 inhibitor- and PRKAA1 agonist-treated HTR-8/SVneo cells was measured by ELISA. (A) Overexpression of miR-137 upregulated the expression levels of IL-6 in HTR-8/SVneo cells. (B) Secretion of IL-6 was elevated in the supernatants of miR-137-overexpressing HTR-8/SVneo cells (C) PRKAA1 inhibitor (dorsomorphin) promoted the production of IL-6 in HTR-8/SVneo cells at different concentrations (2.5, 5 and $10 \mu$ M). (D) PRKAA1 agonist (AICAR; 1.10, 0.25 and $0.50 \mathrm{mM}$ ) suppressed secretion of IL-6 from HTR-8/SVneo cells. Data are expressed as the mean \pm standard error of the mean; statistical significance was determined using Student's t-test or one-way analysis of variance, ${ }^{*} \mathrm{P}<0.05,{ }^{* *} \mathrm{P}<0.01,{ }^{* * *} \mathrm{P}<0.001$. miR-137, microRNA-137; PRKAA1 protein kinase AMP-activated catalytic subunit $\alpha 1$; LV, lentiviral vector; NC, negative control; IL-6, interleukin-6.

A

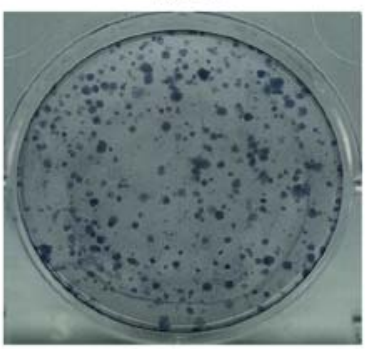

B
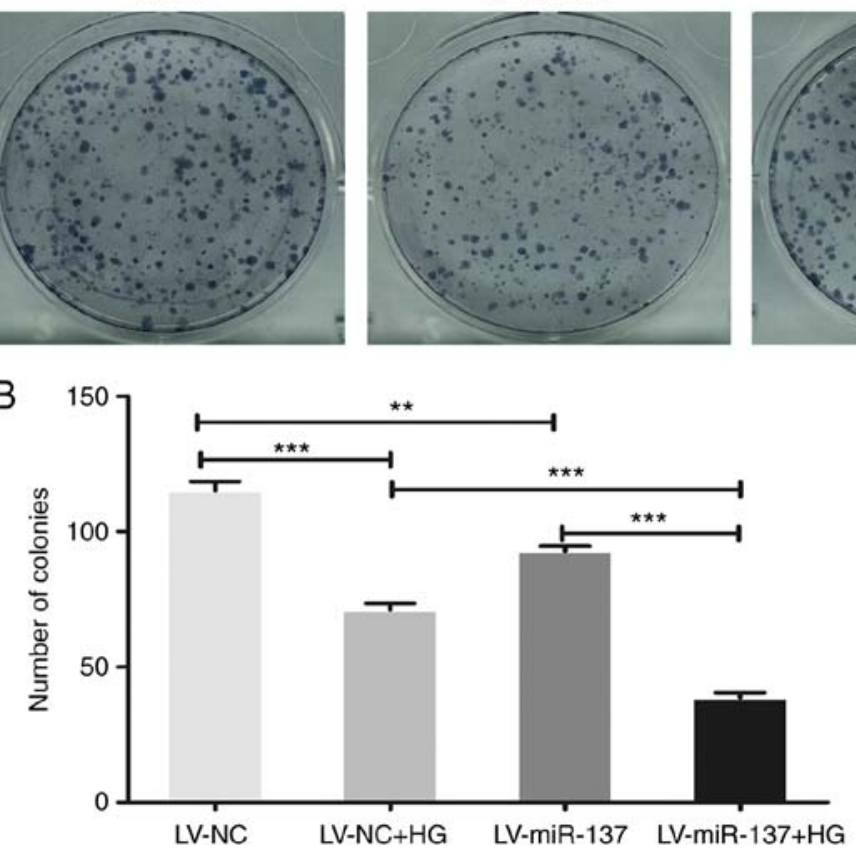

LV-miR-137

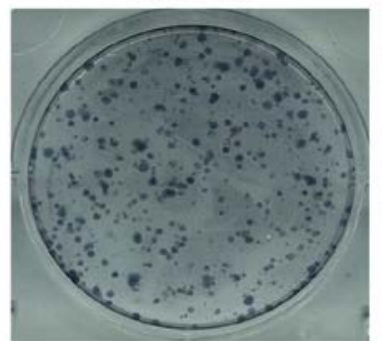

C

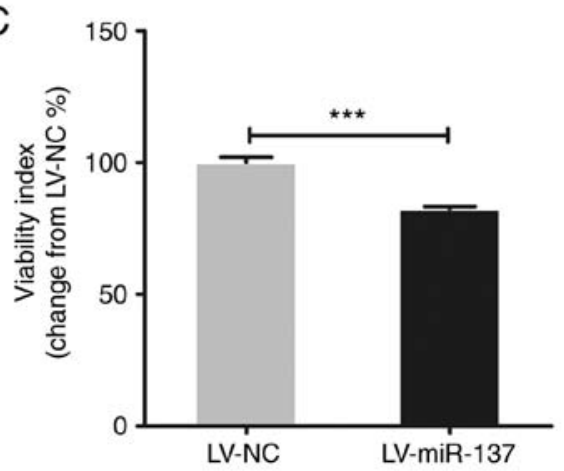

Figure 5. HG/miR-137 reduces viability and proliferation of HTR-8/Svneo cells. The viability and proliferation of HTR-8/SVneo cells were assessed using CCK-8 and colony formation assays. LV-NC and LV-miR-137 HTR-8/SVneo cell groups were treated with normal and HG medium for 10 days for the colony formation assay. (A) Images of the colony formation assay. (B) miR-137/HG suppressed proliferation of HTR-8/SVneo cells. (C) CCK-8 assay demonstrated decreased viability of miR-137-overexpressing HTR-8/SVneo cells. Data are presented as the mean \pm standard error of the mean; statistical significance $(\mathrm{P}<0.05)$ was determined using Student's t-test, ${ }^{* *} \mathrm{P}<0.01,{ }^{* * *} \mathrm{P}<0.001$. CCK-8, Cell Counting Kit-8; HG, high glucose; miR-137, microRNA-137; LV, lentiviral vector; $\mathrm{NC}$, negative control. 
A
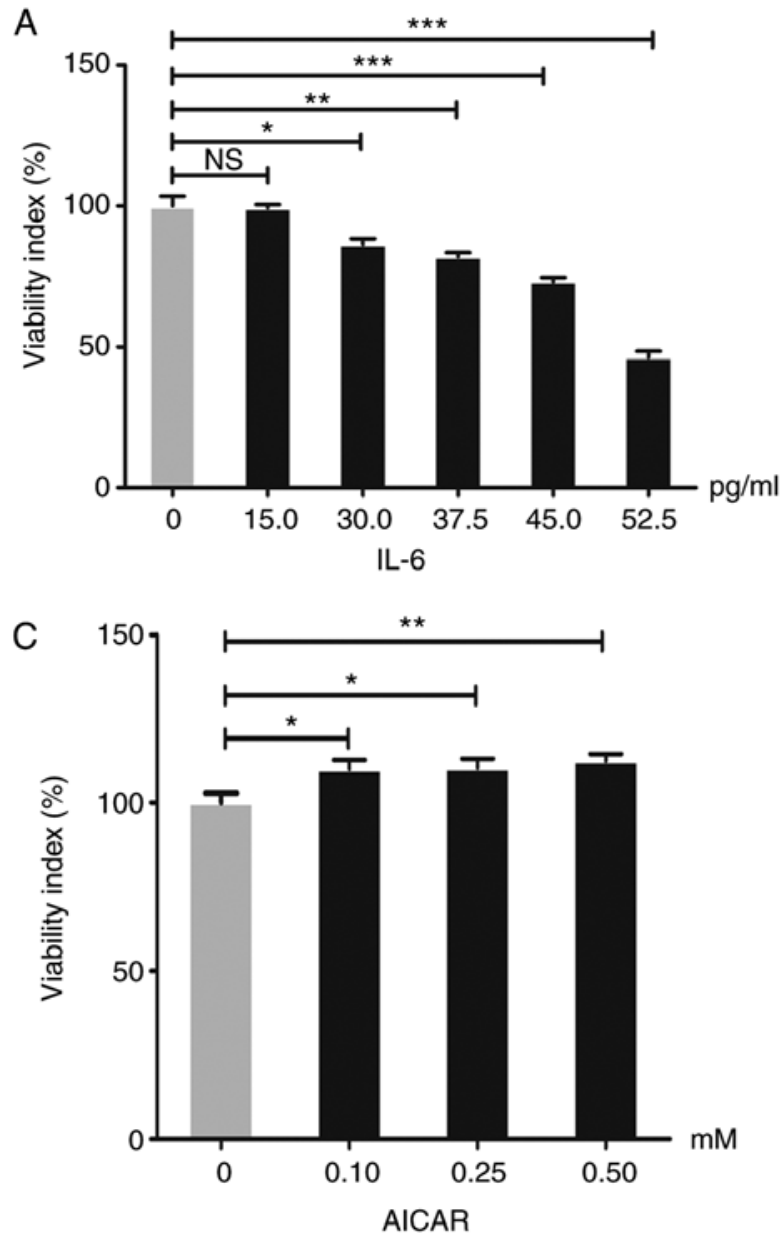

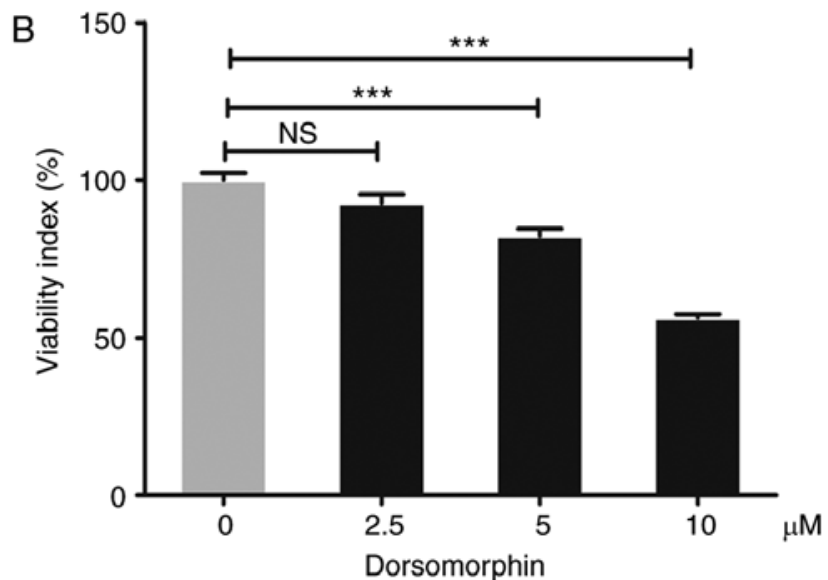

$\mathrm{D}$

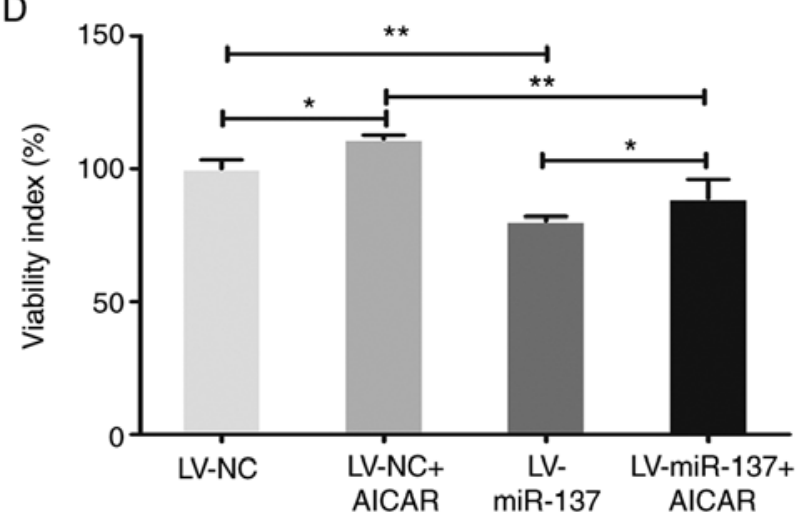

Figure 6. miR-137 suppresses cell viability of HTR-8/SVneo cells by decreasing PRKAA1 and upregulating IL-6. Following cell treatment with different concentrations of IL-6 (15.0, 30.0, 37.545 .0 and $52.5 \mathrm{pg} / \mathrm{ml})$, dorsomorphin $(2.5,5$ and $10 \mu \mathrm{M})$ and AICAR $(0.10,0.25$ and $0.50 \mathrm{mM})$ for $24 \mathrm{~h}$, with untreated cells as a control group, the viability of HTR-8/SVneo cells was measured using a Cell Counting Kit assay. (A) Different concentrations of IL-6 suppressed the viability of HTR-8/SVneo cells. (B) PRKAA1 inhibitor (dorsomorphin) decreased the viability of HTR-8/SVneo cells. (C) PRKAA1 agonist (AICAR) increased the viability of HTR-8/SVneo cells. (D) Inhibition of viability induced by overexpression of miR-137 in HTR-8/SVneo cells was partly reversed by PRKAA1 agonist (AICAR, $0.5 \mathrm{mM}$ ). Data are presented as the mean \pm standard error of the mean; statistical significance $(\mathrm{P}<0.05)$ was determined using Student's t-test or one-way analysis of variance followed Student-Newman-Keuls test, ${ }^{*} \mathrm{P}<0.05,{ }^{* *} \mathrm{P}<0.01,{ }^{* * *} \mathrm{P}<0.001$. NS, no significant difference; miR-137, microRNA-137; PRKAA1 protein kinase AMP-activated catalytic subunit $\alpha 1$; IL-6, interleukin-6p; LV, lentiviral vector; NC, negative control.

IL-6 regulated by miR-137/PRKAAl suppresses the viability and proliferation of HTR-8/SVneo cells. In the present study, it was shown that PRKAA1 may be regulated by miR-137 and affect the production of IL-6. It was then hypothesized that this axis may also be involved in the HG-induced suppression of viability and proliferation of HTR-8/SVneo cells. An antibody of IL-6 ( $\alpha$-IL-6) was used to inhibit the effect of IL- 6 and, as shown in Fig. 7A and $\mathrm{B}$, it was observed that $\alpha$-IL- 6 promoted the proliferation activity of HTR-8/SVneo cells $(\mathrm{P}<0.05)$. Additionally, the results (Fig. 7C and D) suggested that the application of $\alpha$-IL- 6 at different concentrations and times facilitated the viability of the cells $(\mathrm{P}<0.05)$. Whether $\alpha-\mathrm{IL}-6$ was effective against the inhibitor of PRKAA1 (dorsomorphin) was then investigated. The results (Fig. 7E) indicated that $\alpha$-IL- 6 reversed the viability restriction induced by the PRKAA1 inhibitor in HTR-8/SVneo cells $(\mathrm{P}<0.05, \mathrm{P}<0.01$ and $\mathrm{P}<0.001)$. Collectively, these results suggested that $\mathrm{HG}$ suppressed the viability and proliferation of HTR-8/SVneo cells via the miR-137/PRKAA1/IL-6 axis.

\section{Discussion}

The results of the present study confirmed that HG treatment contributed to the suppression of cell viability and proliferation in the HTR-8/SVneo cell line, which is contradictory to the most common clinical cases in which mothers with GDM give birth to macrosomic infants and possess a larger volume of placental tissue (24-26). It has previously been demonstrated that $\mathrm{HG}$ conditions result in the mother and fetus exhibiting 'over-nutrition' and leads to overgrowth of the fetus (27). In addition, if maternal plasma glucose levels continue to increase and remain in a severe hyperglycemic state, cytotoxicity occurs (28). Therefore, it was hypothesized that the suppressive effect of HG on the viability and proliferation of trophoblast cells is associated with the concentration of glucose. In the present study, HG medium was established with a final glucose concentration of $25 \mathrm{mmol} / 1$, in accordance with previous studies $(29,30)$, which is generally used in in vitro experiments for analyzing T2DM, a type of diabetes with symptoms of poor glycemic control and severe insulin 

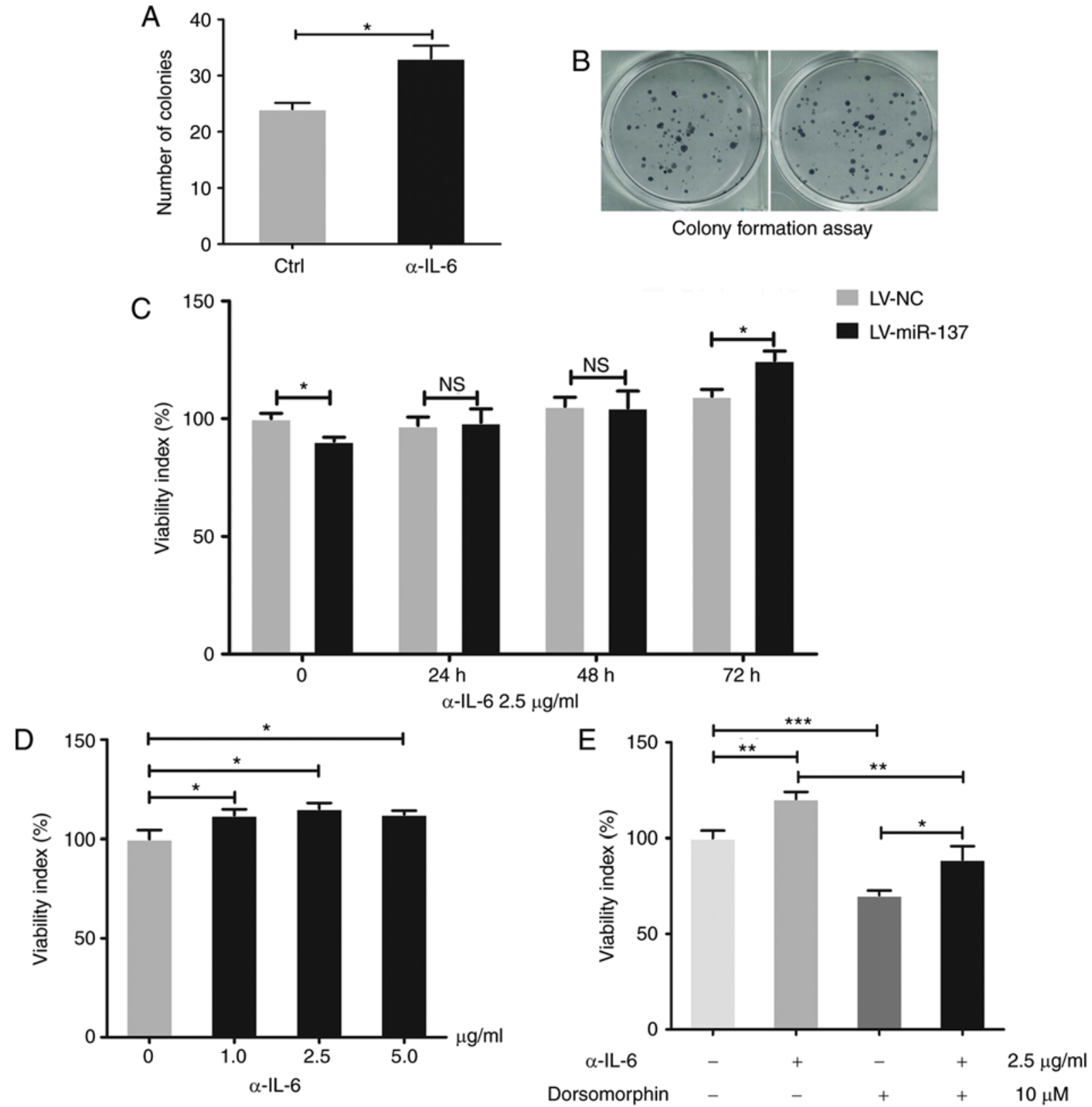

Figure 7. IL-6 regulated by miR-137/PRKAA1 suppresses cell viability and proliferation of HTR-8/SVneo cells. Colony formation and a Cell Counting Kit-8 assays were used to detect the proliferation and viability of HTR-8/SVneo cells, respectively. (A) Proliferation of HTR-8/SVneo cells was enhanced by $\alpha$-IL-6 $(2.5 \mu \mathrm{g} / \mathrm{ml})$ treatment. (B) Images of colony formation assay. (C) Inhibition of viability induced by the overexpression of miR-137 in HTR-8/SVneo cells was reversed by $\alpha$-IL-6 in a time-dependent manner. (D) Treatment with $\alpha$-IL-6 (1.0, 2.5 and $5.0 \mu \mathrm{g} / \mathrm{ml})$ for $24 \mathrm{~h}$ enhanced cell viability of HTR-8/SVneo cells. (E) $\alpha$-IL-6 $(2.5 \mu \mathrm{g} / \mathrm{ml})$ partly reversed the weakened viability of HTR-8/SVneo cells induced by the PRKAA1 inhibitor (dorsomorphin, $10 \mu \mathrm{M})$. Data are expressed as the mean \pm standard error of the mean; statistical significance was determined using Student's $t$-test or one-way analysis of variance, "P<0.05, ${ }^{* *} \mathrm{P}<0.01,{ }^{* * *} \mathrm{P}<0.001$. Ctrl, control; NS, no significant difference; miR-137, microRNA-137; PRKAA1 protein kinase AMP-activated catalytic subunit $\alpha 1$; IL-6, interleukin-6; $\alpha$-IL-6, antibody against IL-6; LV, lentiviral vector; NC, negative control.

resistance (31). However, there is no literature that offers an appropriate glucose concentration to suit the conditions of light-type or pre-state of T2DM or GDM, which occurs during pregnancy and contributes to the largest proportion of cases of HG with adverse pregnancy outcomes (32). Due to this, the present study investigated various cases of pregnant women with poor glycemic control. Few studies have compared the differences in the effects of glucose concentration in vivo and in vitro; therefore, selecting the most suitable glucose concentration to simulate the conditions in vivo remains a challenge and a limitation of the present study. The use of several glucose concentration gradients to reflect different severities of GDM in individuals requires investigation in the future.

Previous studies have investigated the role of PRKAA1 in diabetic/HG conditions. Firstly, PRKAA1 is aberrantly expressed in the skeletal muscle, placenta and human sera of individuals with GDM (33); secondly, it is associated with HG-induced dysfunction of vascular endothelial cells, impaired angiogenesis, cardiovascular complications and obesity-associated insulin resistance (34); and finally, it may be regulated by the diabetes drug metformin (35). Therefore, it was hypothesized that PRKAA1 may also be involved in the insulin 


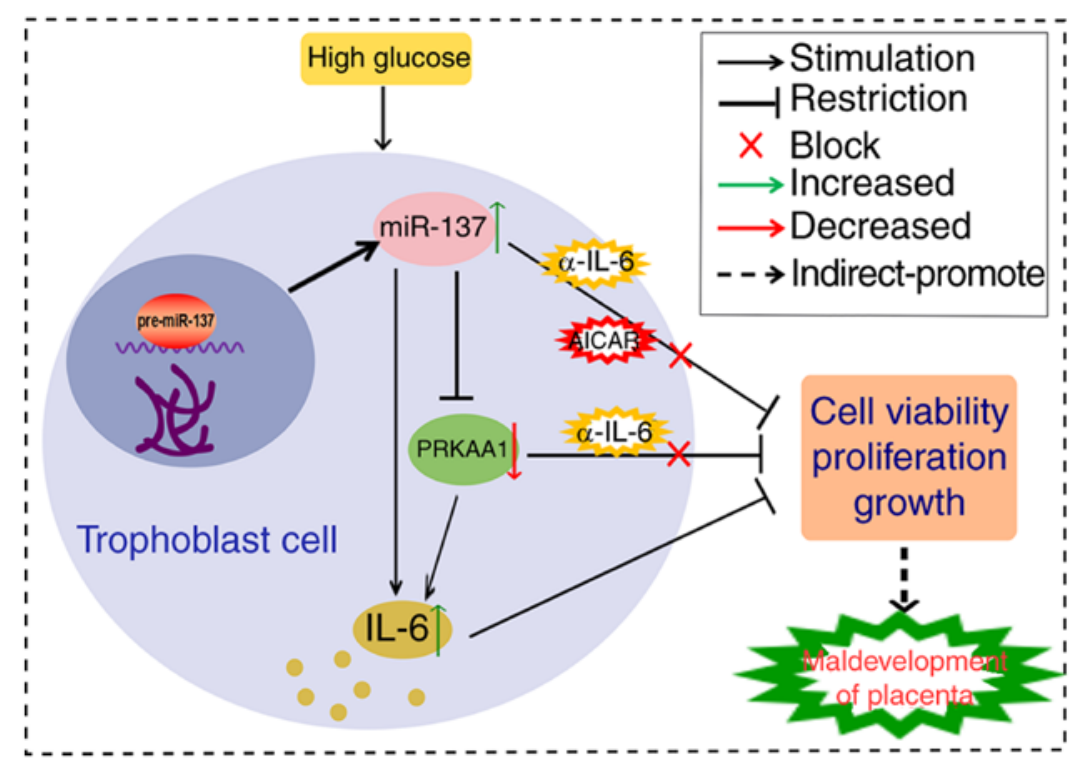

Figure 8. Overall mechanisms of action based on the results of present study. HG treatment upregulated expression levels of miR-137, which resulted in a negative modulatory effect on PRKAA1 and ultimately stimulated the expression of IL-6. HG/miR-137 suppressed the viability and proliferation of HTR-8/SVneo cells; the PRKAA1 inhibitor or upregulated IL-6 had the same effect, and these effects were inhibited by $\alpha$-IL-6. The miR-137/PRKAA1/IL-6 axis was involved in HG-induced suppression of cell viability and proliferation of HTR-8/SVneo cells, which may contribute to maldevelopment of the placenta during gestational diabetes. miR-137, microRNA-137; PRKAA1 protein kinase AMP-activated catalytic subunit $\alpha 1$; IL-6, interleukin-6; $\alpha$-IL-6, antibody against IL-6.

signaling pathway and insulin resistance of HTR-8/SVneo cells, further contributing to the pathological changes of trophoblast cells. It has been reported that a reduction of PRKAA1 may disrupt cellular metabolism in trophoblast cells (36), and that the activation of PRKAA1 promotes maintenance of the utero-placental bloodstream during hypoxic pregnancy (34). The direct effects of decreased PRKAA1 on the proliferation, migration and invasiveness of trophoblast cells have not been investigated extensively previously. To the best of our knowledge, the present study is the first to demonstrate that PRKAA1 may be involved in modulating the viability and proliferation of HTR-8/SVneo cells under HG conditions, and provides a theoretical foundation for future clinical treatment of patients with GDM. However, the present study had various limitations, including a lack of investigation into the role of phosphorylated PRKAA1, which may be an important factor involved in the pathology of the placenta in a gestational diabetic condition.

miR-137 has previously been reported to contribute to the progression of preeclampsia and GDM $(13,14)$, being vital in regulating vascular endothelial and trophoblast cells, involved in various biological processes and HG-induced oxidative stress injury, and a potential biomarker for monitoring the severity of diseases and long-term risk of metabolic disorders. Various studies have investigated the association between gestational diabetic conditions and levels of miR-137, and it has been revealed that $\mathrm{HG}$ gives rise to aberrant expression of miR-137 in various cells and tissues; however, the specific underlying mechanisms involved in this process remain to be elucidated. Certain molecules are involved in regulating miRNAs, and these may also be targeted by miRNAs, which form a loop and radically promote the progression of pathological changes (37). In addition to the abnormal expression of miR-137, methylation of the miR-137 promoter may also contribute to the occurrence and progression of diseases $(38,39)$. Regarding upstream regulatory molecules of miR-137, Forkhead box D3 and high-mobility group AT-hook 1 have been reported to activate the transcription of miR-137 via directly binding to its promoter (40). The mechanism underlying the upregulation of miR-137 under HG conditions remains to be elucidated, although disruption of the miR-137 promoter region may account for this change. Previously demonstrated roles of miR-137 are closely associated with its target genes (41); in the present study, PRKAA1 was significantly downregulated by miR-137, and it is possible that various other unidentified genes are involved in suppressing the viability and proliferation of HTR-8/SVneo cells.

According to previous studies, the role of PRKAA1 in regulating IL-6 is variable in different types of cells. Tang et al (42) demonstrated that an inhibitor of PRKAA1 suppressed adiponectin-induced production of IL-6 in human rheumatoid arthritis synovial and osteoarthritis synovial fibroblasts. Lihn et al (43) observed that an agonist of PRKAA1 decreased levels of IL- 6 in adipose tissues, and was consistent with the results of Lim et al (17), which suggested that the PRKAA1 activator AICAR reduced levels of IL-6 in primary amnion cells. These distinctions may be attributed to the various biological functions of different cells, and the role of PRKAA1 in regulating IL- 6 in trophoblast cells has received limited investigation. The present study demonstrated that the inhibitor of PRKAA1, dorsomorphin, significantly upregulated the expression of IL-6 in HTR-8/SVneo cells, whereas the agonist of PRKAA1, AICAR, exhibited the opposite effect. Based on knowledge of existing signaling pathways associated with PRKAA1, it was established that IL-6 is not a direct target, and the mechanism underlying the PRKAA1-induced regulation of the expression of IL- 6 through intermediate molecules in HTR-8/SVneo cells remains to be fully elucidated. Increased levels of IL-6 have 
been observed in the plasma and various tissues of patients with GDM, which promotes not only low-grade inflammatory reaction, but also disease progression (21). It has previously been demonstrated that IL-6 inhibitor promotes the viability of pancreatic $\beta$-cells (44), whereas elevated IL- 6 induces obesity-related insulin resistance (45), which serves as the etiology for the development of impaired glucose tolerance. Apoptosis and proliferation contribute to the viability of cells, and the present study only clarified that restricted proliferation activity resulted in the decreased viability of HTR-8/SVneo cells; however, the underlying mechanism remains to be elucidated. IL-6 may be involved in maldevelopment of the placenta through suppressing the viability and proliferation of trophoblast cells; the dysfunction of vascular endothelial cells and disrupted angiogenesis induced by IL- 6 may also contribute to the pathology (46). Notably, upstream or downstream molecules of IL-6 may act as ideal therapeutic targets for intervention of GDM, particularly if the expression levels of these molecules are associated with the severity of diseases.

In conclusion, as shown in Fig. 8, the HG of a gestational diabetic condition suppressed the viability and proliferation of HTR-8/SVneo cells through the miR-137/PRKAA1/IL-6 axis, and this may contribute to the pathology of trophoblast cells during the diabetic period. Whether this leads to maldevelopment of the placenta and adverse pregnancy outcomes requires verification in vivo through animal experiments. The present study aimed to provide an underlying mechanism for the dysfunction of trophoblast cells in conditions of hyperglycemia, and to provide a theoretical foundation for future therapeutic treatments for mothers with GDM.

\section{Acknowledgements}

The authors would like to thank Professor Da-Jin Li of Fudan University (Shanghai, China) for his assistance in study design.

\section{Funding}

This study was supported by the Natural Science Foundation of Shanghai (grant no. 12ZR1422200) and the Research Fund of Shanghai Jiao Tong University Affiliated Sixth People's Hospital (grant no. LYZY-0053).

\section{Availability of data and materials}

The datasets used and/or analyzed during the current study are available from the corresponding author on reasonable request.

\section{Authors' contributions}

HL conceptualized the study design. HP acquired the data and drafted the manuscript. ML contributed to the study design and revised the manuscript.

\section{Ethics approval and consent to participate}

The present study was approved by the Ethics Committee of Shanghai Jiao Tong University Affiliated Sixth People's Hospital. All participants provided informed consent.

\section{Consent for publication}

All authors reviewed multiple drafts of the paper and approved the final manuscript for publication.

\section{Competing interests}

The authors declare that they have no competing interests.

\section{References}

1. Kleinwechter $\mathrm{H}$ and Demandt $\mathrm{N}$ : Diabetes in pregnancy-type 1/type 2 diabetes mellitus and gestational diabetes mellitus. Dtsch Med Wochenschr 141: 1296-1303, 2016 (In German).

2. Bánhidy F, Acs N, Puhó EH and Czeizel AE: Congenital abnormalities in the offspring of pregnant women with type 1 , type 2 and gestational diabetes mellitus: A population-based case-control study. Congenit Anom 50: 115-121, 2010.

3. Callec R, Perdriolle-Galet E, Sery GA and Morel O: Type 2 diabetes in pregnancy: Rates of fetal malformations and level of preconception care. J Obstet Gynaecol 34: 648-649, 2014.

4. Kaiser J: Gearing up for a closer look at the human placenta. Science 344: 1073, 2014.

5. Zong S, Li C, Luo C, Zhao X, Liu C, Wang K, Jia W, Bai M, Yin M, Bao S, et al: Dysregulated expression of IDO may cause unexplained recurrent spontaneous abortion through suppression of trophoblast cell proliferation and migration. Sci Rep 27: 19916, 2016.

6. Tian FJ, Qin CM, Li XC, Wu F, Liu XR, Xu WM and Lin Y: Decreased stathmin-1 expression inhibits trophoblast proliferation and invasion and is associated with recurrent miscarriage. Am J Pathol 185: 2709-2721, 2015.

7. Liong S and Lappas M: Activation of AMPK improves inflammation and insulin resistance in adipose tissue and skeletal muscle from pregnant women. J Physiol Biochem 71: 703-717, 2015.

8. Li J, Li J, Wei T and Li J: Down-regulation of MicroRNA-137 improves high glucose induced oxidative stress injury in human umbilical vein endothelial cells by up-regulation of AMPK $\alpha 1$. Cell Physiol Biochem 39: 847-859, 2016.

9. Yao G, Zhang Y, Wang D, Yang R, Sang H, Han L, Zhu Y, Lu Y, Tan Y and Shang Z: GDM-induced macrosomia is reversed by Cav-1 via AMPK-mediated fatty acid transport and GLUT1-mediated glucose transport in placenta. PLoS One 12: e0170490, 2017.

10. Chen H, Lan HY, Roukos DH and Cho WC: Application of microRNAs in diabetes mellitus. J Endocrinol 222: R1-R10, 2014.

11. Haertle L, El Hajj N, Dittrich M, Müller T, Nanda I, Lehnen $\mathrm{H}$ and Haaf T: Epigenetic signatures of gestational diabetes mellitus on cord blood methylation. Clin Epigenetics 9: 28, 2017.

12. Ornoy A, Reece EA, Pavlinkova G, Kappen C and Miller RK: Effect of maternal diabetes on the embryo, fetus, and children: Congenital anomalies, geneticand epigenetic changes and developmental outcomes. Birth Defects Res C Embryo Today 105: 53-72, 2015.

13. Li J, Song L, Zhou L, Wu J, Sheng C, Chen H, Liu Y, Gao S and Huang W: A MicroRNA signature in gestational diabetes mellitus associated with risk of macrosomia. Cell Physiol Biochem 37: 243-252, 2015.

14. Lu TM, Lu W and Zhao LJ: MicroRNA-137 affects proliferation and migration of placenta trophoblast cells in preeclampsia by targeting ERR $\alpha$. Reprod Sci: pii: 1933719116650754, 2016.

15. Lappas M: Double stranded viral RNA induces inflammation and insulin resistance in skeletal muscle from pregnant women in vitro. Metabolism 64: 642-653, 2015.

16. Kim SY, Jeong S, Jung E, Baik KH, Chang MH, Kim SA, Shim JH, Chun E and Lee KY: AMP-activated protein kinase- $\alpha 1$ as an activating kinase of TGF- $\beta$-activated kinase 1 has a key role in inflammatory signals. Cell Death Dis 3: e357, 2012.

17. Lim R, Barker G and Lappas M: Activation of AMPK in human fetal membranes alleviates infection-induced expression of pro-inflammatory and pro-labour mediators. Placenta 36: 454-462, 2015. 
18. Huang NL, Chiang SH, Hsueh $\mathrm{CH}$, Liang YJ, Chen YJ and Lai LP: Metformin inhibits TNF-alpha-induced Ikappa-B kinase phosphorylation, IkappaB-alpha degradation and IL-6 production in endothelial cells through PI3K-dependent AMPK phosphorylation. Int J Cardiol 134: 169-175, 2009.

19. American Diabetes Association: Diagnosis and classification of diabetes mellitus. Diabetes Care 35 (Suppl 1): S64-S71, 2012.

20. Livak KJ and Schmittgen TD: Analysis of relative gene expression data using real-time quantitative PCR and the $2^{-\Delta \Delta C_{\mathrm{T}}}$ method. Methods 25: 402-408, 2001.

21. Daniele G, Guardado Mendoza R, Winnier D, Fiorentino TV, Pengou Z, Cornell J, Andreozzi F, Jenkinson C, Cersosimo E, Federici M, et al: The inflammatory status score including IL-6, TNF- $\alpha$, osteopontin, fractalkine, MCP-1 and adiponectin underlies whole-body insulin resistance and hyperglycemia in type 2 diabetes mellitus. Acta Diabetol 51: 123-131, 2014.

22. Bigham AW, Julian CG, Wilson MJ, Vargas E, Browne VA, Shriver MD and Moore LG: Maternal PRKAA1 and EDNRA genotypes are associated with birth weight, and PRKAA1 with uterine artery diameter and metabolic homeostasis at high altitude. Physiol Genomics 46: 687-697, 2014.

23. He C, Li H, Viollet B, Zou MH and Xie Z: AMPK suppresses vascular inflammation in vivo by inhibiting signal transducer and activator of transcription-1. Diabetes 64: 4285-4297, 2015.

24. Visiedo F, Bugatto F, Sánchez V, Cózar-Castellano I, Bartha JL and Perdomo G: High glucose levels reduce fatty acid oxidation and increase triglyceride accumulation in human placenta. Am J Physiol Endocrinol Metab 305: E205-E212, 2013.

25. Wang LF, Wang HJ, Ao D, Liu Z, Wang Y and Yang HX: Influence of pre-pregnancy obesity on the development of macrosomia and large for gestational age in women with or without gestational diabetes mellitus in Chinese population. J Perinatol 35: 985-990, 2015.

26. Jarmuzek $P$, Wielgos $M$ and Bomba-Opon D: Placental pathologic changes in gestational diabetes mellitus. Neuro Endocrinol Lett 36: 101-105, 2015.

27. Leng J, Li W, Zhang S, Liu H, Wang L, Liu G, Li N, Redman LM, Baccarelli AA, Hou L and Hu G: GDM women's pre-pregnancy overweight/obesity and gestational weight gain on offspring overweight status. PLoS One 10: e0129536, 2015.

28. Sedlic F, Muravyeva MY, Sepac A, Sedlic M, Williams AM, Yang M, Bai X and Bosnjak ZJ: Targeted modification of mitochondrial ROS production converts high glucose-induced cytotoxicity to cytoprotection: Effects on anesthetic preconditioning. J Cell Physiol 232: 216-224, 2017.

29. Kuricová K, Pácal L, Šoupal J, Prázný M and Kaňková K: Effect of glucose variability on pathways associated with glucotoxicity in diabetes: Evaluation of a novel in vitro experimental approach. Diabetes Res Clin Pract 114: 1-8, 2016.

30. Liu J, Chen S, Ren W, Liu J, Yang P, Chen Z, Zhang Q and Yang F: Lipopolysaccharide-induced suppression of periodontal ligament cell proliferation and apoptosis are strengthened under high glucose conditions. Arch Oral Biol 79: 70-76, 2017.

31. Abdallah AM, Alves BC, Gehrke FS, Sant' Ana AV, Azzalis LA Junqueira VB, Adami F, Pereira EC and Fonseca FL: Inability of turbidimetry method in detecting glycated hemoglobin to select diabetes mellitus patients according to their concentrations of blood glucose levels. J Clin Lab Anal 29: 312-316, 2015.

32. Pedersen ML, Olesen J, Jørgensen ME and Damm P: Gestational diabetes mellitus in Greenland: A national study of prevalence and testing efficacy. Int J Circumpolar Health 75: 32167, 2016.

33. Wojtaszewski JF, Birk JB, Frøsig C, Holten M, Pilegaard H and Dela F: 5'AMP activated protein kinase expression in human skeletal muscle: Effects of strength training and type 2 diabetes. J Physiol 564: 563-573, 2005.
34. Song YM, Lee YH, Kim JW, Ham DS, Kang ES, Cha BS, Lee HC and Lee BW: Metformin alleviates hepatosteatosis by restoring SIRT1-mediated autophagy induction via an AMP-activated protein kinase-independent pathway. Autophagy 11: 46-59, 2015.

35. Waker CA, Albers RE, Pye RL, Doliboa SR, Wyatt CN, Brown TL and Mayes DA: AMPK knockdown in placental labyrinthine progenitor cells results in restriction of critical energy resources and terminal differentiation failure. Stem Cells Dev 26: 808-817, 2017.

36. Zhang L, Han YJ, Zhang X, Wang X, Bao B, Qu W and Liu J: Luteolin reduces obesity-associated insulin resistance in mice by activating ampk $\alpha 1$ signaling in adipose tissue macrophages. Diabetologia 59: 2219-2228, 2016.

37. Floris I, Descamps B, Vardeu A, Mitić T, Posadino AM, Shantikumar S, Sala-Newby G, Capobianco G, Mangialardi G, Howard L, et al: Gestational diabetes mellitus impairs fetal endothelial cell functions through a mechanism involving microRNA-101 and histone methyltransferase enhancer of zester homolog-2. Arterioscler Thromb Vasc Biol 35: 664-674, 2015.

38. Dang J, Bian YQ, Sun JY, Chen F, Dong GY, Liu Q, Wang XW, Kjems J, Gao S and Wang QT: MicroRNA-137 promoter methylation in oral lichen planus and oral squamous cell carcinoma. J Oral Pathol Med 42: 315-321, 2013.

39. Langevin SM, Stone RA, Bunker CH, Lyons-Weiler MA, LaFramboise WA, Kelly L, Seethala RR, Grandis JR, Sobol RW and Taioli E: MicroRNA-137 promoter methylation is associated with poorer overall survival in patients with squamous cell carcinoma of the head and neck. Cancer 117: 1454-1462, 2011.

40. Liu LL, Lu SX, Li M, Li LZ, Fu J, Hu W, Yang YZ, Luo RZ, Zhang CZ and Yun JP: FoxD3-regulated microRNA-137 suppresses tumour growth and metastasis in human hepatocellular carcinoma by targeting AKT2. Oncotarget 5: 5113-5124, 2014.

41. Han F, Wang S, Chang Y, Li C, Yang J, Han Z, Chang B, Sun B and Chen L: Triptolide prevents extracellular matrix accumulation in experimental diabetic kidney disease by targeting microRNA-137/Notch1 pathway. J Cell Physiol 233: 2225-2237, 2018.

42. Tang CH, Chiu YC, Tan TW, Yang RS and Fu WM: Adiponectin enhances IL-6 production in human synovial fibroblast via an AdipoR1 receptor, AMPK, p38, and NF-kappa B pathway. J Immunol 179: 5483-5492, 2007.

43. Lihn AS, Jessen N, Pedersen SB, Lund S and Richelsen B: AICAR stimulates adiponectin and inhibits cytokines in adipose tissue. Biochem Biophys Res Commun 316: 853-858, 2004.

44. Paula FM, Leite NC, Vanzela EC, Kurauti MA, Freitas-Dias R, Carneiro EM, Boschero AC and Zoppi CC: Exercise increases pancreatic $\beta$-cell viability in a model of type 1 diabetes through IL-6 signaling. FASEB J 29: 1805-1816, 2015.

45. Almuraikhy S, Kafienah W, Bashah M, Diboun I, Jaganjac M, Al-Khelaifi F, Abdesselem H, Mazloum NA, Alsayrafi M, Mohamed-Ali V and Elrayess MA: Interleukin-6 induces impairment in human subcutaneous adipogenesis in obesity-associated insulin resistance. Diabetologia 59: 2406-2416, 2016.

46. Qu D, Liu J, Lau CW and Huang Y: IL-6 in diabetes and cardiovascular complications. Br J Pharmacol 171: 3595-3603, 2014.

This work is licensed under a Creative Commons Attribution-NonCommercial-NoDerivatives 4.0 International (CC BY-NC-ND 4.0) License. 